\title{
Guidelines to Integrate BIM for Asset and Facility Management of a Public University
}

\author{
Giuseppe Martino Di Giuda, Paolo Ettore Giana, Marco Schievano \\ and Francesco Paleari
}

\begin{abstract}
This research work aims at providing a methodological approach tested on a real case study, where a public university applied guidelines to structure BIM and IMM procedures. The research allows the public client to procure works and services to manage the portfolio. The approach is initially tested on the ABC department to be gradually extended to the entire Politecnico di Milano.
\end{abstract}

Keywords Portfolio information management - Public administration client • Data-driven process $\cdot$ Asset information model (AIM) $\cdot$ Organizational information requirements (OIR)

\section{Introduction}

The effective implementation of a new methodology such as BIM has repercussions on the entire value chain of an industrial sector: for this reason, it requires a planned and structured intervention by the legislator to encourage its adoption. European Union BIM Task Group aims at aligning the national programmes in order to adapt national programmes and spread information modelling among European community, boosting public administration's productivity.

The EUBIMTG (2018) supports the need for collaboration in the development of national programmes by sharing the results achieved by individual nations. Thus, the most effective and efficient measures can be repeated in countries that share a uniform market, speeding up the implementation process. According to the literature and to main consulting company (McKinsey Global Institute 2017; The Ellen MacArthur Foundation 2012; Barbosa et al. 2017), the public administrations have an important role in the implementation of BIM methodology in playing in the digital transition process, defining guidelines to regulate the BIM methodology and address the sector. In a process where the path is not well defined, international standards have to set

G. M. Di Giuda $(\varangle)$ · P. E. Giana · M. Schievano · F. Paleari

Architecture, Built Environment and Construction Engineering-ABC Department,

Politecnico di Milano, Milan, Italy

e-mail: giuseppe.digiuda@polimi.it

B. Daniotti et al. (eds.), Digital Transformation of the Design, Construction and Management Processes of the Built Environment, Research for Development, https://doi.org/10.1007/978-3-030-33570-0_28 
principles to follow rather than impose strategies. It is up to the single Appointing Parties to define the strategies that drive procurement processes. The EUBIMTG (2018), through the strategic framework for BIM implementation process, recognizes the task of the public client to decrease the frequency and mitigate the impact of factors that act negatively against the success of the BIM implementation process. In the strategic development and guidance framework for the AECO sector, it identifies the following four areas of intervention: (i) definition of the public strategy to increase support for the BIM methodology; (ii) communication of the vision and promotion of communities to increase interest and participation; (iii) development of a collaborative framework to improve the sharing and transparency of information; and (iv) growth of the expertise of clients and the sector to improve the process in technical aspects.

The EUBIMTG identifies the need to reform the regulatory framework of building processes to support the collaboration principle of the BIM methodology by encouraging the information exchange among the parties involved. The public client has the function of identifying critical issues in the data sharing and the process transparency to support the legislative bodies in the drafting and publication of appropriate laws or transpose EU directives to reduce problems. The public client is entrusted with the task of increasing the BIM skills and competencies of the sector through pilot projects and direct adoption of the BIM methodology in public contracts.

\section{Information Management According to International Standard}

Information management (i.e. the integration, distribution and coordination of information) plays a key role in modern production processes. The literature (McKinsey Global Institute 2017; The Ellen MacArthur Foundation 2012; Barbosa et al. 2017) shows that it is possible to improve the final project result through the development of the information management skills inside the organization and of the information outside the company. In fact, the information management improvement results in greater management effectiveness, efficiency, quality and flexibility (Liu et al. 2015).

The British Standards Institution (BSI 2018) recognizes the added value of the BIM methodology, summarized in the ability to reduce the project time and cost and the work and the management costs recreation during the entire asset life cycle, through a standardized approach to information management.

Effective information management within the client's processes favours their optimisation and operational performance during the asset use phase. Structuring the information production of a client allows producing coherent information between the different projects and operators involved. The information production outside the organization assures better management of internal processes, activating greater collaboration and transparency that is reflected in the overall projects improvement, 
both internal and external. Transparency and collaboration during the activities performance allow organizations involved to assess the risks arising from their activities and the activities of employees. Namely, this process reduces the risk level in the production of information. It is, therefore, necessary that the contracting authority structures a BIM process in order to improve the information produced by the different economic operators. On these grounds, the new EN ISO 19650 part 1 and 2 are the new international guidelines to define the process of organizing and digitizing information through the BIM methodology for the management of civil and construction engineering works (Fig. 1). The objective of the concepts and principles defined is to reduce risks costs associated with the asset management of buildings, complexes and infrastructure. The functions of these organizations, in the context of a public procedure, are covered by the contracting authorities acting on behalf of the public administrations they represent. The BIM methodology requires even before starting a project process to make explicit the information requests related to the final objective, i.e. the information to be obtained in order to achieve this objective.

In this context, the client plays a fundamental role as the person in charge of defining the objectives of the project and the requirements to be met. For this reason, the drafting of strategic objectives whose requirements are expressed in the OIR. It influences both maintenance decisions whose requirements are expressed in the AIR and all project decisions whose requirements are expressed in the EIR. The expression of needs at different levels allows, to standardize the approach that an organization has to Asset Management strategies.

Once the contracting station has selected the different Lead Appointed Parties, the project process begins. As mentioned above, this process must take place within an

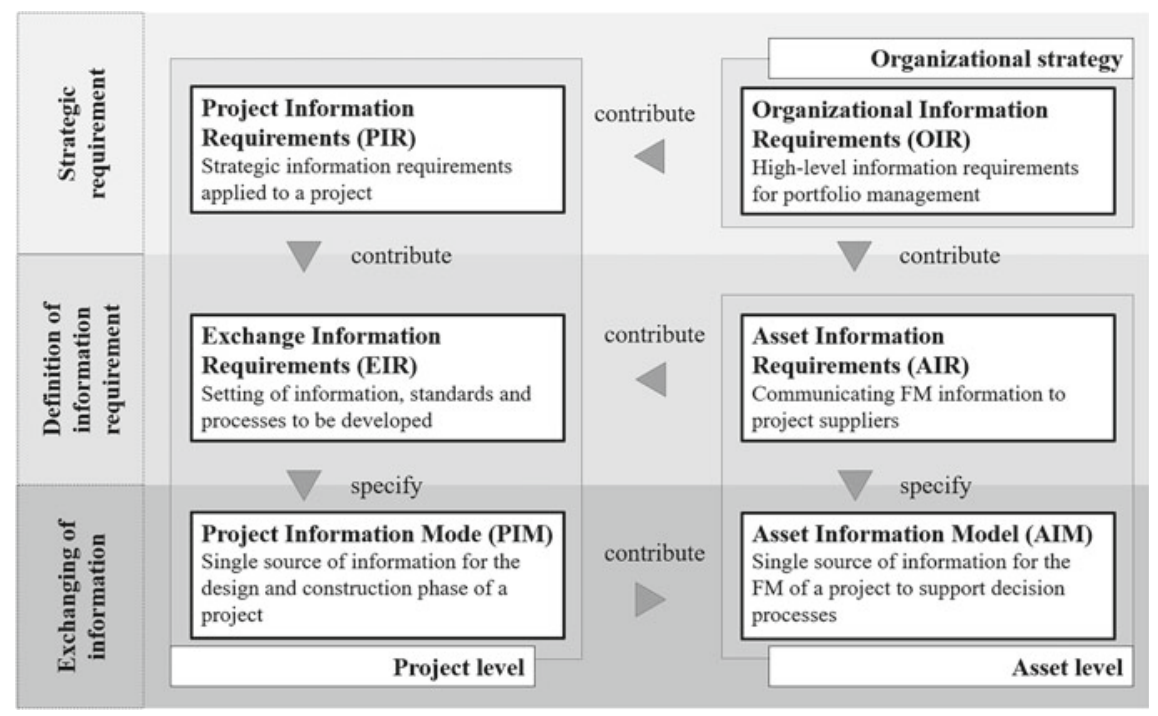

Fig. 1 Information workflow according to ISO19650-1 
information-sharing platform Common Data Environment. The BIM methodology, reported in the ISO 19650 series, requires the contracting authority to be the first party to produce information. The contracting authority is, in fact, responsible for objectives defining and information requirements at the starting point of a project. The information requirements determine the types, times and methods of information that must be produced, necessary for the contracting authority to support the decisions set in each milestone. There is, therefore, a significant change whereby the design phases are no longer only conceived as levels of definition to be achieved, but as key moments when certain decisions must be taken. These moments are defined as project milestones.

As it is necessary to clarify from the very beginning the objective of applying the BIM in a building intervention the definition of an application strategy to achieve this aim is crucial. The definition of the BIM use required for the project under analysis represents the starting point for the definition of the phases and documents to be produced later. The definition of the project intended use is based on the concept of 'starting with the end in mind': a profound paradigm shift linked to the transition to BIM.

\section{State of the Art of International Guidelines for Information Modelling}

Considering the advantages provided by a BIM approach, different Countries have adopted different strategies in implementing the methodology. The most advanced clients have a structured programme for the BIM implementation, and are equipped with standards for data management and information modelling. The creation of proprietary guidelines is to be considered positive as it allows clients to develop project information requirements in a structured way, according to processes driven by a specific organizational requirement (Di Giuda et al. 2017).

The most advanced Countries have engaged in the definition of proprietary guidelines for specific clients (e.g. Finland (European Construction Sector Observatory 2016), Norway (Statsbygg 2011), Singapore (BCA 2017) and USA (US Dept of Veterans Affairs 2017; Bloomberg et al. 2012; Los Angeles World Airports 2017; USC Capital Construction Development and Facilities Management Services 2012; Massachusetts Institute of Technology 2016)).

Namely since 2007, Finland has imposed a progressive obligation on BIM for public works, and in 2014 one of the first proprietary guideline for the construction and management of bridges was published. This guideline, published by the Finnish Transport Agency, incorporates what is presented in the CoBIM standard (European Construction Sector Observatory 2016) and specifies the process and the BIM requirements for the government body activity in charge of the Finnish infrastructure management. 
On the other side, the General Service Administration (GSA) published in the early century a guideline for the management activities of public offices in the USA. The guidelines have been partially updated and conformed to the standard published by the National Institute of Building Science (NIBS) (BuildingSMART alliance 2015).

Later on, also the government body Building and Construction Authority (BCA) (2017) of Singapore publishes the guideline for the design, construction and management phases with the related objectives of use. This document gives an overall view of the issues to be developed in the BIM implementation, defining in general terms the results to be achieved.

The Statsbygg in Norway draws up the first guideline for the implementation of the BIM methodology in projects managed by the institution. This guide aims at defining the information requirements, generic and specific disciplines, to facilitate the control and management of the process by the customer.

Unlike the Countries mentioned above, others have undertaken to define national regulations which, however, do not present the operating instructions for achieving the benefits deriving from the methodology (Hooper 2015). In this sense, the internal management of an organization, defined by standardized approaches, does not allow to obtain the most from the BIM approach, in terms of efficiency and attitudes of professionals. The definition of proprietary guidelines allows to standardize and guide processes based on the needs of a specific client.

\section{Research Methodology}

This research describes the process of digital transition of a public university in managing its own asset through a BIM approach (Fig. 2). The methodology started with the definition of the requirements of the Appointing Party, ABC Department of Politecnico di Milano, and develops with the definition of client proprietary BIM guidelines for asset management. This approach guides the specific client in the transition from a traditional approach to a BIM methodology. It activates a computational transition process to improve the design, construction, maintenance, and management quality: using BIM models and connected databases, accessing and obtaining data from any building and creating a dynamic archive of documents for each settlement are transition key steps. These models have been connected to external databases to better manage historical data about buildings and their components.

The first initial effort is devoted to the analysis of procedures and data workflows to identify main requirements, objectives, and useful information of the organization, aiming at improving data exchange and storage.

The next step has been the analysis of existing assets, based on drawings and documents provided. A Working Breakdown Structure (WBS) has been set up to identify, for each building system, all objects and components connected, with a hierarchical structure. From the database and the drawings supplied, the spaces and buildings codification has been taken. The soft-landing approach provides a smooth transition linking new procedures with the old ones, keeping the same codification 


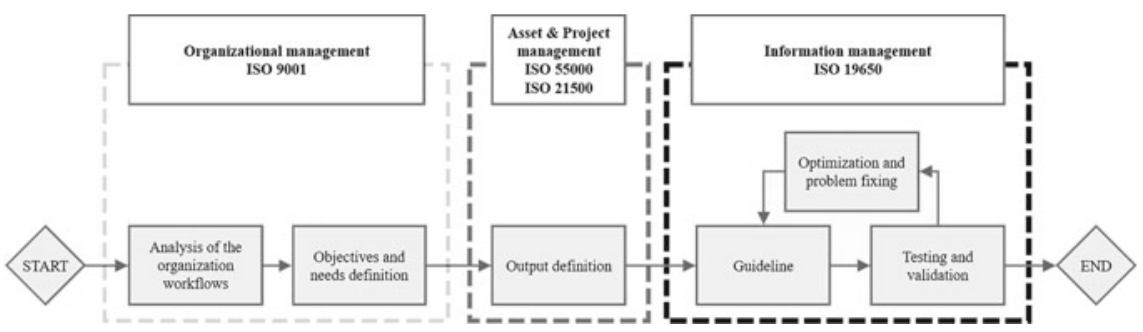

Fig. 2 Methodology approach

rule has also been required in the past, even though setting a complete dataset to every object.

A BIM Library has been created for architectural, structural and MEP system. The dataset were mainly divided in categories: (i) codification; (ii) generic information (description, model, pictures, etc.); (iii) specifications (current, voltage, frequency, etc.); and (iv) maintenance. The attributes come from COBie (British Standards Institution 2014) dataset, organization's and maintenance requirements and consultant experiences gained in past projects.

The guideline has been written for the following major existing guidelines and the ISO 12911:2012, in order to have a guideline tailored to client's needs, but is also valid at international level. The guideline was tested on a real case study, as described in the following paragraph.

\section{Case Study}

The BIM guidelines have been applied to the ABC Department (Architecture, Built environment and Construction engineering) building, representative of the Politecnico di Milano portfolio. The three-storey building is divided into two main wings with a connection, for a total of $4300 \mathrm{~m}^{2}$ of gross floor area. The case study is a pilot project for the guideline validation. After the validation phase, the main goal is to gradually extend the guideline to the entire Politecnico di Milano building asset.

The guideline flexibility allows the building to be modelled without comprehensive data from all three disciplines: architecture, structure and systems (MEP). Since the structural designs were not available, only visually detectable structures were modelled in the architectural BIM model, without changes in the guideline structure and in the modelling workflow. This information can be added during further investigations in the structural component. 


\subsection{Geometric and Non-geometric Data Survey for the Creation of a BIM Library}

The survey has been conducted following rules set in the guidelines. The objectives, methods and geometric and informative data collected structure depend directly on the organizational structure and management requirements of the organization's asset management. Survey sheets were prepared with the predefined dataset for each asset elements to be recorded.

The building has been surveyed in order to update and correct the as-built and design drawings provided: a detailed survey has been performed to gather all the finishing of each space. Information related to floor, wall, and ceiling finishes is a key data for the asset management. A detailed survey has been performed to validate number and type of security, fire alarm systems, light bulb and every maintainable asset. The equipment maintenance and use of information were collected at the same time as the geometric survey.

After the survey and identification of architectural, structural and MEP disciplines elements, the BIM library was built and organized. The information requirements for management and maintenance were linked to the modelled objects. Attributes are inserted in objects thanks to shared parameters file, to allow the implementation and application in other new objects. Attributes are standardized and organized into following categories: (i) project information; (ii) codification; (iii) general data; (iv) fire prevention equipment; (v) electrical equipment; (vi) mechanical equipment; (vii) spaces; and (viii) maintenance.

\subsection{Master Model and DataBase}

The master model's main purpose is the geometric information coordination and visualization, while the data management is carried out in the individual discipline BIM models. Discipline models are linked to the master model through a system of shared coordinates; this guarantees the correct spatial alignment of the models.

The links between the discipline models affect the database structure which is identical to the model's structure, so there is a Database (DB) of the architectural, structural and MEP data connected in a master DB.

The BIM model-DB connection is bi-univocal to link each object instance to historical data. For instance, there is the possibility to easily: (i) attach photos taken during the survey to the instances of the objects; (ii) attach data sheets or other documents to object types; (iii) attach documents to the entire building or settlement, so as to have a digital archive; (iv) manage data on scheduled and performed maintenance; and (vi) manage data about objects condition, installation and end life date. This connection also allows us to dynamically update data, filling them in the database without a BIM authoring tool, and graphically checking them in the model, thanks to thematic plans and dedicated filters in the BIM model (Fig. 3). 
Fig. 3 Master BIM model

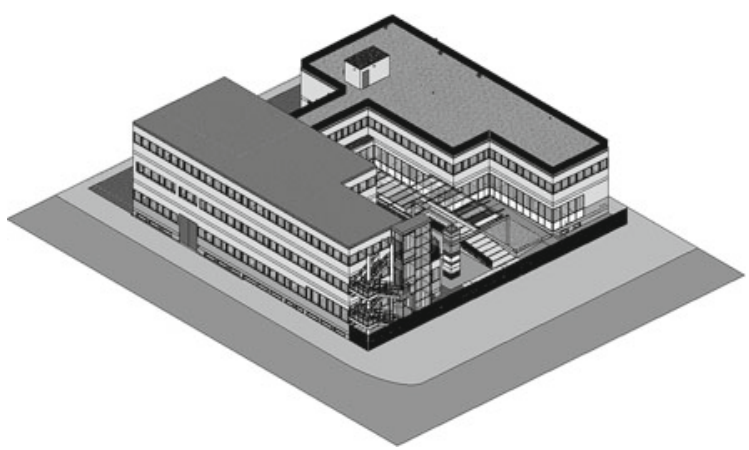

\subsection{Model Output}

The BIM models output, such as thematic plans, schedules, views (sections, plans, prospects, etc.), has been set up to meet client objectives. The databases also have outputs and thanks to the software, they used can be customized according to users' needs: queries, tables and data elaboration can be extracted from the database.

An interesting output is the finishing materials bill, that can be used as the starting point for conducting a tender for cleaning services. All the output have been defined in the guidelines, where also the operational procedures to produce new ones are also described.

Existing buildings frequently need to be modified, so the guideline has been set up to regulate the information exchange in case of internal layout modification.

The office 012 layout changes have been modelled to test the procedures, workflows and tools developed. Geometrical and non-geometrical data were consistent and updated at all stages (Fig. 4).

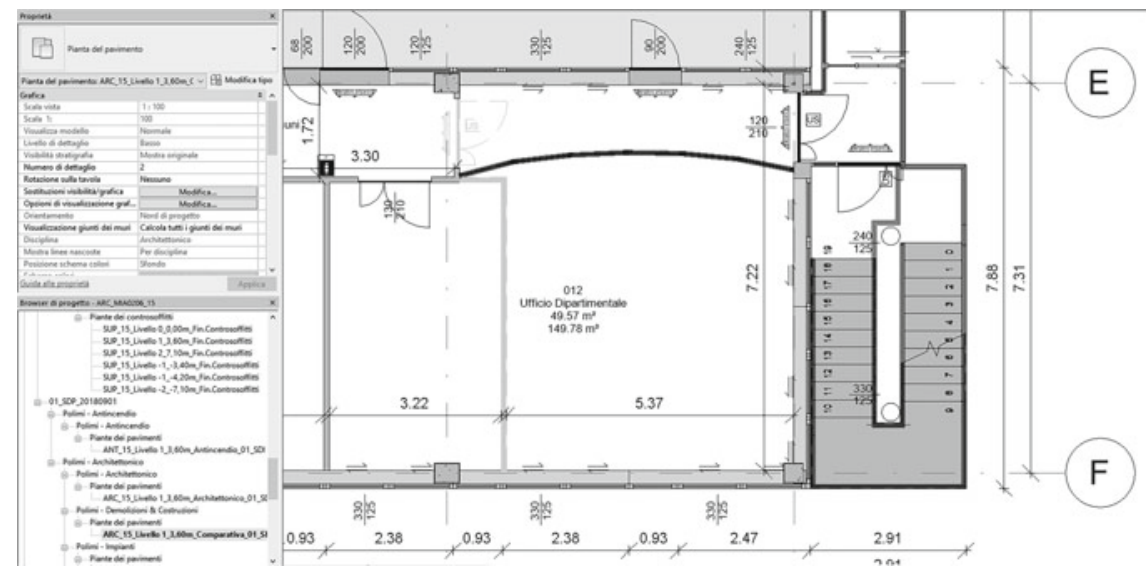

Fig. 4 Example of a layout modification 


\section{Discussion and Further Development}

This paper presents a research aiming at creating a guideline for managing existing assets of Politecnico di Milano portfolio, and for easing design of new construction. To reach this goal, OIRs have been divided into packages, easier to handle, and then translated into AIRs and eventually into attributes of the BIM models and of the connected databases.

This methodology allows to control a series of fundamental processes, such as (i) managing relevant information about existing buildings and new constructions; (ii) managing documents of the entire assets; (iii) monitoring maintenance and operation phases; (iv) standardizing projects information thanks to a detailed LoIN; (v) controlling data exchange among parties thanks to robust procedures; and (vi) extracting output useful portfolio management. The authors planned to revise and improve the guideline with Appointing party's feedbacks.

The customization of procedures, according to client's requirements, allows a soft-landing approach to the BIM methodology that otherwise is rarely and reluctantly accepted by the structured organization. The guidelines are used as a tender specification to manage different procurement according to common strategy of the organization achieving the consistency among data produced in different situations.

The future development of the research project is the definitions of an optimization method for the management of real estate assets, based on the usage model of the building, through a Post-Occupancy Evaluation, that could make it possible to collect data and define the usage model. The presence of cameras connected to a neural platform transforms images into data useful to define the usage model. Once the model usage of the spaces has been defined, the data collected into the BIM model can be used to define and optimize cleaning operations and contracts.

\section{References}

Barbosa F, Woetzel J, Mischke J, Ribeirinho MJ, Sridhar M, Parsons M, Bertram N, Brown S (2017) Reinventing construction: a route to higher productivity. McKinsey Co, p 168

BCA (2017) Singapore VDC Guide

Bloomberg MR, Burney DJ, Resnick D (2012) BIM Guidelines

British Standards Institution (2014) BS 1192-4:2014 Collaborative production of information Part 4 : Fulfilling employer's information exchange requirements using $\mathrm{COBie}-\mathrm{Code}$ of practice BSI (2018) Gov.uk 1

BuildingSMART alliance (2015) National BIM Standard for The United States V3

Di Giuda GM, Giana PE, Villa V (2017) Comparison between different collaborative procurement methods: a system for integrating building information modelling in AEC processes. Constr Eng Manag

EUBIM Task Group (2018) Handbook for the introduction of building information modelling by the European Public Sector

European Construction Sector Observatory (2016) Finland: coBIM Requirements

Hooper M (2015) BIM standardisation efforts—-the case of Sweden. J Inf Technol Constr 20:332346 
Liu H, Al-Hussein M, Lu M (2015) BIM-based integrated approach for detailed construction scheduling under resource constraints. Autom Constr 53:29-43. https://doi.org/10.1016/j.autcon. 2015.03.008

Los Angeles World Airports (2017) Volume 2: Requirements for building information modeling

Massachusetts Institute of Technology (2016) MIT Design Standards-BIM and CAD Drawing Standards v6.0

McKinsey Global Institute (2017) Reinventing construction: a route to higher productivity

Statsbygg (2011) Statsbygg BIM manual 1.2. Bim 1.2.1:98

The Ellen MacArthur Foundation (2012) Towards a circular economy-economic and business rationale for an accelerated transition. Greener Manag Int 97. doi:2012-04-03

US Dept of Veterans Affairs (2017) VA BIM Standard

USC Capital Construction Development and Facilities Management Services (2012) University of Southern California BIM Guidelines for Design-Bid Build Contracts

Open Access This chapter is licensed under the terms of the Creative Commons Attribution 4.0 International License (http://creativecommons.org/licenses/by/4.0/), which permits use, sharing, adaptation, distribution and reproduction in any medium or format, as long as you give appropriate credit to the original author(s) and the source, provide a link to the Creative Commons license and indicate if changes were made.

The images or other third party material in this chapter are included in the chapter's Creative Commons license, unless indicated otherwise in a credit line to the material. If material is not included in the chapter's Creative Commons license and your intended use is not permitted by statutory regulation or exceeds the permitted use, you will need to obtain permission directly from the copyright holder. 